\title{
Studies on locally available three anti-diabetic herbal medicines
}

\author{
Mohammad Shoeb, Naznin Nahar, Farouq Ahmed, M. Mosihuzzaman and Nilufar Nahar
}

Department of Chemistry, University of Dhaka, Dhaka 1000, Bangladesh.

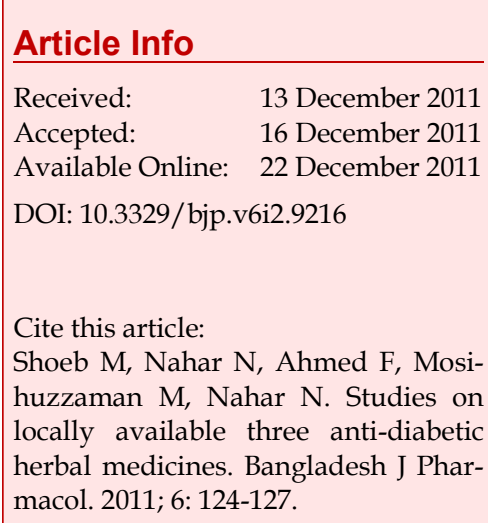

\begin{abstract}
Herbal medicines are being used for the treatment of different diseases for centuries. Sustainable development of herbal medicines need the study of their safety, efficacy and standardization are essential. Two commercially available herbal medicines i.e., Ziabetes (dolabi) and Jambadayrist, and a folkloric medicine prepared from four plant materials by a local practitioners were investigated for their chemical compositions. Four compounds were isolated from the extracts of these medicines by silica gel column chromatography. Oleic acid and $p$-hydroxycinnamic acid were isolated from the aqueous $80 \%$ ethanol extract of the folkloric medicine whereas benzoic acid was found to be present in Ziabetes and Jambadayrist. The present investigation revealed that excessive amount of benzoic acid (or sodium benzoate) is being added as preservative in commercial herbal medicines.
\end{abstract}

\section{Introduction}

Use of medicinal plants for treatment of different ailments is as old as human civilization. Africa, Australia and Asia are the three continents where traditional medicine became popular and $\sim 80 \%$ of the people in the developing countries are still dependent on plant based medicines (TDR 2005; Newman et al., 2000). The medicines are termed as herbal medicines which are prepared either from aerial parts of herbs or the whole plant or parts of plants i.e., barks, leaves, roots, stems, flowers, fruits and seeds. Herbal products may contain a single herb or combination of several different herbs (Mosihuzzaman and Choudhary, 2008). In case of multiple plants it is believed that the efficacy is due to synergistic effects. Raw herbs are available in the market and the formulated products of the herbs are prepared following different pharmacopeia (Mosihuzzaman and Choudhary, 2008).

Although some of the modern medicines are affordable by the low income people of least developed countries, a large number of people still rely and like to use plant medicine like Ayurvedic and Unani medicine in the Indian Sub-continent, and Traditional Chinese Medicine in China. Besides that, the herbs are also very popular in the developed countries (De Smet, 2005). Many herbal medicines, herbs and herbal products are available in the USA, Japan (Kampo), and European countries (Fisher and Ward, 1994). People use herbs as complementary or integrating medicine along with prescribed drugs. In the recent times, African and Asian nations encourage traditional medicine as an integral component of their public health care programs as they are relatively inexpensive, locally available and are readily accepted by the local population.

Diabetes, a non-communicable heterogeneous group of disorders, is the third major cause of death after cancer and heart diseases. Currently 3.2 million people die every year from diabetic complications. It has been estimated that by 2025, diabetic patients will be over 300 million around the world posing a major challenge to the healthcare and social welfare (Wild et al., 2004). No new medicine is discovered to combat diabetes after discovery of metformin and sulphoryl urea and its 
derivatives. Plant materials and/or herbal drugs are considered as alternative source for the management of diabetes. However, the safety, efficacy and standardization of herbal medicines are to be assessed to make them acceptable as an essential component of public health care. The objective of the present work is to determine chemical compositions of two commercially available herbal antidiabetic medicines i.e., Ziabetes (dolabi) and Jambadayrist and a folkloric medicine prepared by a local practitioner who treats his patients for diabetes in Jessore area.

\section{Materials and Methods}

\section{Instrument}

UV and IR spectra were recorded on Shimadzu UV 160A and Shimadzu IR-470 spectrometer, respectively. The ${ }^{1} \mathrm{H}$ and ${ }^{13} \mathrm{C}$ NMR spectra were recorded on a Bruker $400 \mathrm{MHz}$ spectrometer using tetramethylsilane as the internal reference.

\section{Collection of herbal medicine}

Ziabetes (dolabi) and Jambadayrist, two commercial antidiabetic herbal medicines were purchased from the herbal medicinal shop of Dhaka city. Folkloric medicine, a combination of four plant materials i.e. Nigella sativa, Piper nigrum, Achyranthes aspera and Sida spinosa was supplied by a medicine man who prepares it in the form of pellet (bori) and treats his patients for diabetes management.

\section{Extraction procedure}

Herbal preparation (pellets; $250 \mathrm{~g}$ ) was mixed thoroughly and extracted with aqueous $80 \%$ ethanol $(100 \mathrm{~mL} x$ 3 ) at room temperature for 24 hours. The extract was collected by suction filtration, evaporated into dry mass by a rotavapor at bath temperature below $40^{\circ} \mathrm{C}$. Residual solvent from the dried material was removed by freeze dryer to obtain $40 \mathrm{~g}$ of extract.

Jambadayrist $(100 \mathrm{~mL})$, liquid herbal preparation was partitioned with dichloromethane (dichloromethane; $150 \mathrm{~mL} \times 3$ ). The dichloromethane soluble part was collected and evaporated into dry mass by a rotavapor at bath temperature below $40^{\circ} \mathrm{C}$. Residual solvent from the dried material was removed by freeze dryer to get $320 \mathrm{mg}$ of dichloromethane soluble part.

Ziabetes (dolabi), solid herbal preparation (200 g) was ground in powdered and extracted with dichloromethane (3 times, 24 hours, at room temperature). The combined extract was evaporated to dryness to get $9.8 \mathrm{~g}$ of dichloromethane extract. The residue was further extracted with methanol (3 times, 24 hours, room temperature). The methanol extract was evaporated to dryness and $13.0 \mathrm{~g}$ of methanol extract was obtained.

\section{Isolation of compounds}

The ethanol extract ( $10 \mathrm{~g})$ of the folkloric medicine was dissolved completely in a mixture of dichloromethane and methanol and $20 \mathrm{~g}$ of silica gel (70-230 mesh size) was added to the solution. The resulting slurry was evaporated to dryness by rotary vacuum evaporator. The dried material was finally mixed thoroughly in mortar and pestle. A column was packed with silica gel using hexane as column equilibrating solvent and the dried sample was applied to column and eluted with nhexane, dichloromethane and methanol with increasing polarity. One fraction collected from $80 \%$ dichloromethane in hexane gave single spot in TLC, it was purified by repeated washing with $n$-hexane and a pure compound I (34 mg) was obtained. Another fraction eluted with dichloromethane:methanol (1:1) was further fractionated by silica gel column using dichloromethane and methanol as eluting solvent and compound II (15 mg) was obtained from 5\%methanol in dichloromethane elution.

The dichloromethane extract (300 mg) of Jambadayrist was fractionated by silica gel column following the same way using dichloromethane as column equilibrating solvent and elution was performed by dichloromethane and methanol with increasing polarity. A single compound (III, $30 \mathrm{mg}$ ) was isolated from the column when eluted with $15 \%$ methanol in dichloromethane.

The dichloromethane extract ( $1 \mathrm{~g}$ ) of Ziabetes (dolabi) was also fractionated by silica gel column following the same procedure i.e. using $n$-hexane, dichloromethane and methanol with successive increasing of solvent polarity for elution of the compounds. A fraction eluted with $80 \%$ dichloromethane in hexane, gave single spot in TLC and was collected as pure compound IV (20.0 mg) after washing with $n$-hexane. Another fraction eluted with $15 \%$ methanol in dichloromethane gave single spot which was collected as pure compound. Structure elucidation showed that it was same to the compound III.

\section{Properties of the isolated compounds}

Compound I: Light yellow, gummy, UV (dichloromethane): $\lambda_{\max }$ at $237 \mathrm{~nm}$, IR (KBr pellets): 2900, 1700, 1450, 940, $720 \mathrm{~cm}^{-1} .{ }^{1} \mathrm{H} \mathrm{NMR}\left(\mathrm{CDCl}_{3}\right): \delta 5.33$ (m), $5.32(\mathrm{~m}), 2.75(\mathrm{~m}), 2.34(\mathrm{~m}), 2.04(\mathrm{~m}), 1.61(\mathrm{~m}), 1.29$ (m) and $0.84(\mathrm{t}, J=6.9 \mathrm{~Hz})$ ppm. ${ }^{13} \mathrm{C} \mathrm{NMR}\left(\mathrm{CDCl}_{3}\right): \delta$ 180.0, 131.1, 128.1, 34.1, 31.9, 31.7, 31.5, 31.1, 30.0, 29.7, 29.6, 29.3, 29.2, 29.1, 27.2, 25.6, 22.6, $14.0 \mathrm{ppm}$.

Compound II: White powder, UV (dichloromethane): $\lambda$ max at 215, 235, $315 \mathrm{~nm}$, IR (KBr pellets): 3450, 2900, 1720, 1520, 1450 and $720 \mathrm{~cm}^{-1}$. ${ }^{1} \mathrm{H}$ NMR $\left(\mathrm{CDCl}_{3}\right): \delta 8.09(\mathrm{~d}$, $J=16 \mathrm{~Hz}, 1 \mathrm{H}), 7.68(\mathrm{~d}, J=7.6,2 \mathrm{H}),, 7.48(\mathrm{~d}, J=7.6 \mathrm{~Hz}, 2 \mathrm{H})$, $6.33(\mathrm{~d}, \mathrm{~J}=16 \mathrm{~Hz}, 1 \mathrm{H}) \mathrm{ppm}$. 


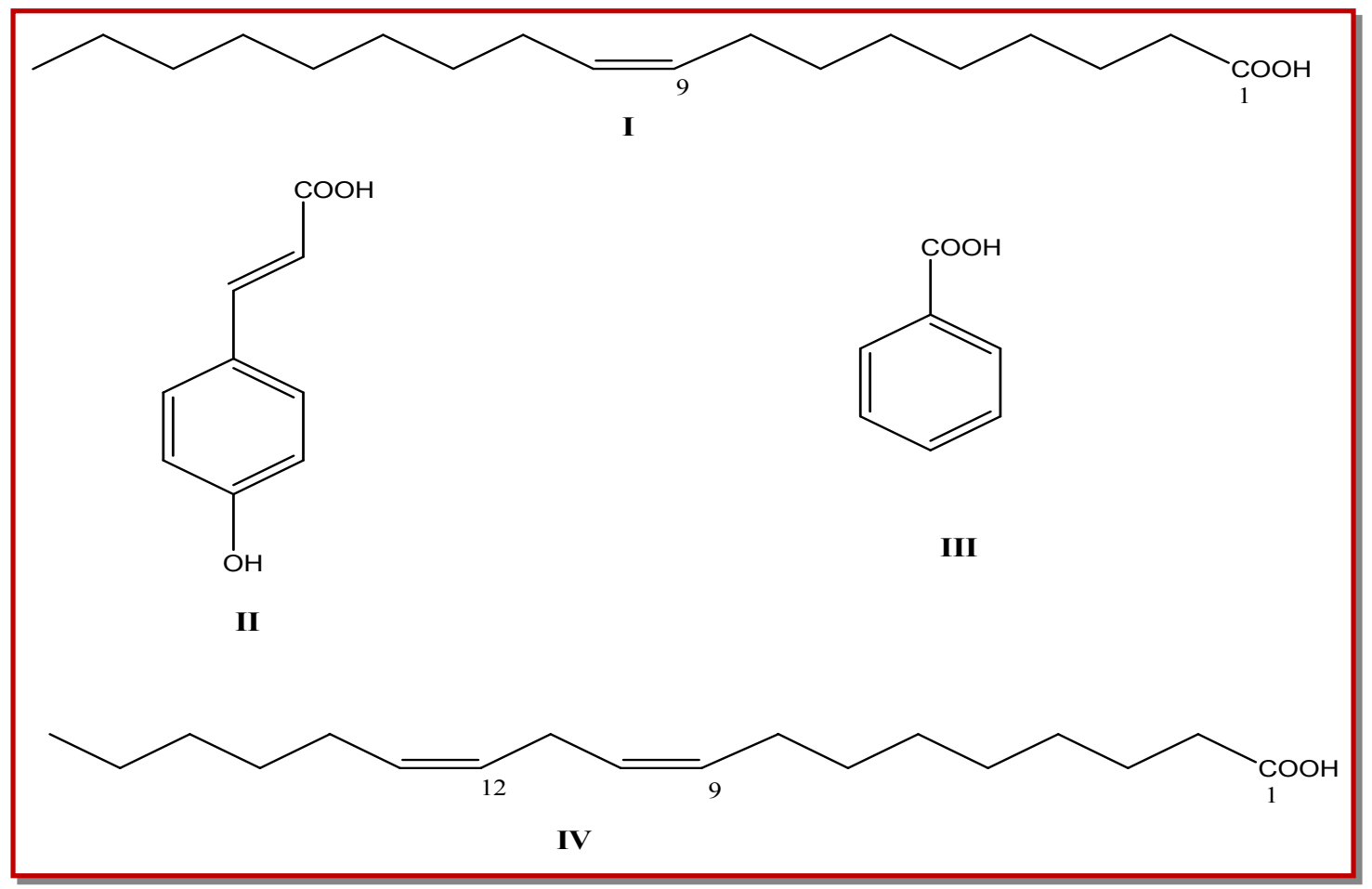

Figure 1: Chemical structure of compounds (I-IV)

Compound III: White solid, M.P. $119^{\circ} \mathrm{C}$, UV (dichloromethane): $\lambda_{\max }$ 233.0, $274.0 \mathrm{~nm}, \mathrm{IR}$ (KBr pellets): 2920, 1770, 1642, 1530, $1245 \mathrm{~cm}^{-1}$. ${ }^{1} \mathrm{H}$ NMR $\left(\mathrm{CDCl}_{3}\right): \delta 8.11(\mathrm{~d}, J=8.0 \mathrm{~Hz}, 2 \mathrm{H}), 7.61(\mathrm{t}, J=7.2 \mathrm{~Hz}, 1 \mathrm{H})$, $7.47(\mathrm{t}, J=7.2 \mathrm{~Hz}, 2 \mathrm{H}) \mathrm{ppm},{ }^{13} \mathrm{C} \mathrm{NMR}\left(\mathrm{CDCl}_{3}\right): \delta 171.9$, $133.8,130.2,130.2,129.3,128.5,128.5$ ppm.

Compound IV: Yellow colored, gummy, UV (dichloromethane): $\lambda_{\max }$ at $237 \mathrm{~nm}, \mathrm{IR}$ (KBr pellets): 2900, 1700, 1450, 940, $720 \mathrm{~cm}^{-1} .{ }^{1} \mathrm{H}$ NMR $\left(\mathrm{CDCl}_{3}\right): \delta 5.33$ (m), $5.11(\mathrm{~m}), 2.76(\mathrm{~m}), 2.27(\mathrm{~m}), 2.03(\mathrm{~m}), 1.83(\mathrm{~m}), 1.67$, $1.30(\mathrm{~m})$ and $0.88(\mathrm{t}, J=6.9 \mathrm{~Hz}) \mathrm{ppm},{ }^{13} \mathrm{C} \mathrm{NMR}\left(\mathrm{CDCl}_{3}\right): \delta$ 174.0, 130.2, 130.1, 128.1, 127.9, 31.9, 31.5, 31.3, 29.8, 29.7, $29.6,29.3,29.2,29.1,27.2,25.7,22.6,14.0 \mathrm{ppm}$.

\section{Results and Discussion}

Compounds I, II, and III were isolated from the dichloromethane soluble part of aqueous $80 \%$ ethanol extract of folkloric medicine and dichloromethane soluble part of Jambadayrist, respectively by silica gel column chromatography. The compound I gave IR absorption at 2900, 1700 and $1450 \mathrm{~cm}^{-1}$ for the presence of $\mathrm{CH}_{3-},-\mathrm{COOH}$ and $-\mathrm{C}=\mathrm{C}$ - groups, respectively. ${ }^{1} \mathrm{H}$ NMR spectrum of I had signals at $\delta 11.3,5.3$ and 5.3, 2.3 -1.3 and $0.8 \mathrm{ppm}$ for the presence of carboxylic acid, olefinic protons, methylenes and methyl group, respectively. The ${ }^{13} \mathrm{C}$ NMR spectral data at $\delta 180.0,131.1$ and 128.1, 34.1-22.6 and 14.0 ppm revealed that carboxylic group, olefinic carbons and methyl group were present in I and was characterized as 9-octadecenoic acid or oleic acid (Shoeb et al., 2010). The compound II had UV absorption maxima, $\lambda_{\max }$ at 215, 235, $315 \mathrm{~nm}$ and suggested the presence of aromatic ring. The IR absorption at 3450,1720, 1520 and $1450 \mathrm{~cm}^{-1}$ indicated the presence of hydroxyl group, carboxylic acid and unsaturation, respectively. ${ }^{1} \mathrm{H}$ NMR spectral data at $\delta$ 8.1 and 6.3 ppm indicated the presence of two protons with olefinic carbons. The higher coupling constant $(J=16 \mathrm{~Hz})$ suggested for trans $(Z)$ configuration (Shoeb et al., 2006). The signals at 7.7 and $7.5 \mathrm{ppm}$ having coupling constants $7.6 \mathrm{~Hz}$ in the ${ }^{1} \mathrm{H}$ NMR spectrum indicated the presence of 1,4 disubstituted benzene ring structure in II. Thus, II was characterized as $p$-hydroxy cinnamic acid. $p$-Hydroxy cinnamic acid is a common secondary metabolites usually found in plant materials due to biosynthetic pathway (Haddock et al., 1982).

The ${ }^{1} \mathrm{H}$ NMR spectrum of compound III showed signals at $\delta 8.11(J=8.0 \mathrm{~Hz}), 7.61(J=7.6,7.4 \mathrm{~Hz})$, and $7.47(J=7.6$, $7.5 \mathrm{~Hz})$ ppm and indicated the presence of substituted benzene ring structure. The ${ }^{13} \mathrm{C}$ NMR and DEPT-135 also revealed the presence of substituted benzene and a carboxylic group by signals at 133.8, 130.2, 130.2, 129.3, 128.5, 128.5 and 171.9 ppm, respectively. From UV, IR, ${ }^{1} \mathrm{H}$ and ${ }^{13} \mathrm{C}$ NMR compound III was characterized as benzoic acid.

Silica gel column chromatography of the dichloromethane extract of Ziabetes also afforded benzoic acid 
(III) and compound IV. UV, IR and ${ }^{1} \mathrm{H}$ and ${ }^{13} \mathrm{C}$ NMR spectral data of compound IV were similar to that of I with additional double bond which was confirmed by signals at $\delta 5.1$ (overlapping double bond) and 130.1 and $127.9 \mathrm{ppm}$, respectively in the ${ }^{1} \mathrm{H}$ and ${ }^{13} \mathrm{C} \mathrm{NMR}$ spectrum, and compound IV was characterized as 9,12octadecadienoic acid or linoleic acid. Linoleic acid is a omega 6 fatty acid which is reported to be beneficial for health related to diabetes type 2 (Ugar et al., 2010). Our present study revealed that benzoic acid was the main component in the commercial grade herbal medicine. Usually, benzoic acid and sodium benzoate is used as preservative in herbal medicine.

\section{Acknowledgement}

The project was financially supported by the International Program in the Chemical Sciences (IPICS), Uppsala University, Sweden.

\section{References}

De Smet PAGM. Herbal medicine in Europe: Relaxing regulatory standards. New Engl J Med. 2005; 54: 801-40.

Fisher P, Ward A. Complementary medicine in Europe. Brit Med J. 1994; 309: 107-11.
Haddock EA, Gupta RK, Al-Shafi SMK, layden K, Haslam E, Magnolato D. The metabolism of gallic acid and hexahydroxydiphenic acid in plants: Biogenetic and molecular taxonomic considerations. Phytochem 1982; 21: 1049-62.

Mosihuzzaman M, Choudhary MI. Protocols on safety, efficacy, standardization, and documentation of herbal medicine. Pure Appl Chem. 2008; 80: 2195-230.

Newman DJ, Cragg GM, Snader KM. The influence of natural products upon drug discovery. Nat Prod Rep. 2000; 17: 21534.

Shoeb M, Begum S, Mamun MIR, Nahar N, Study of an endophytic fungus from Aquilaria malaccensis Lamk. J Bangladesh Chem Soc. 2010; 23: 101-07.

Shoeb M, MacManus S M, Jaspars M, Trevidadu J, Nahar L, Kong-Thoo-Lin P, Sarker SD. Montamine a unique dimeric indole alkaloid, from the seeds of Centaurea montana (Asteraceae), and its in vitro cytotoxic activity against the CaCo2 colon cancer cells. Tetrahedron 2006; 62: 11172-77.

TDR. Operational guidance: Information needed to support clinical trials of herbal products. UNICEF/UNDP/World Bank/WHO Special Program for Research and Training in Tropical Diseases (TDR), 2005.

Ugar G, Chris S. n-3 Omega fatty acids: A review of current knowledge. Inter J Food Sci Tech. 2010; 45: 417-36.

Wild S, Roglic G, Green A, Sicree R, King H. Global prevalence of diabetes: Estimates for the year 2000 and projections for 2030. Diabetes Care, 2004; 27: 1047-53. 